\title{
Legislando sobre o esporte: as comissões permanentes da Câmara dos Deputados em foco*
}

Recebido: 13.03 .20 Aprovado: 31.07 .20

\author{
Mariana Zuaneti Martins** \\ Vitor Vasquez ${ }^{* * *}$
}

Resumo: Pesquisas sobre política pública esportiva no Brasil focam majoritariamente no Poder Executivo. Com o Legislativo fora desse escopo, o campo apresenta uma lacuna, dada a influência que este pode exercer. Ao se considerar as comissões como lócus de atuação do Legislativo, o objetivo foi analisar se a atuação da comissão responsável pelo esporte, quando especializada, promovia com maior expertise a temática. Para tanto, verificamos como o padrão dos atores e de suas atividades modificou-se, entre 2003 a 2018, com o desmembramento da Comissão de Turismo e Desporto (CTD), em 2014, que originou a Comissão de Esporte (Cespo), justificado pela realização dos megaeventos no país. Por meio de análise descritiva e de regressão logística, demonstramos que a criação da Cespo, ao individualizar a temática esportiva, aumentou o interesse dos atores na comissão, a especialização das atividades, o volume de matérias analisadas e a diversidade de temas, gerando mudanças que permanecem mesmo após a realização dos megaeventos.

Palavras-chave: Esporte. Políticas públicas. Poder Legislativo. Comissões permanentes. Especialização.

\section{Sports lawmaking:}

Lower House standing committees in focus

Abstract: Researches on sports public policy in Brazil use to focus on the executive branch. Keeping the legislature out of the scope, the field presents a gap, given the influence that this branch can have. Considering the committees as locus of decision making by the legislature, the aim was to analyze whether the performance of the committee responsible for sport, when specialized, promoted the theme with greater expertise. Therefore, we verified how the pattern of the actors and their activities changed, between 2003 and 2018, considering the split of CTD (Tourism and Sports), in 2014, which gave rise to Cespo (Sports), justified by the holding of mega-events in Brazil. Through descriptive analysis and logistic regression, we demonstrated that the creation of Cespo, by individualizing the sports thematic, increased interest of the actors in the committee, the specialization of activities, the volume of analyzed bills and the diversity of themes, generating changes that remain even after the mega-events.

Keywords: Sport. Public policy. Legislative branch. Standing committees. Specialization.

\author{
* Este trabalho \\ contou com apoio da \\ Fundação de Amparo \\ à Pesquisa do \\ Estado de São Paulo \\ (Fapesp) - projeto \\ n²018/00013- \\ 9 - e do programa \\ Piic/Ufes. As \\ opiniões, hipóteses \\ e conclusões ou \\ recomendações \\ expressas neste \\ material são de nossa \\ responsabilidade e \\ não necessariamente \\ refletem a visão da \\ Fapesp.

** Mariana
Zuaneti Martins é
professora adjunta
da Universidade
Federal do Espírito
Santo (Ufes), Vitória,
Espírito Santo,
Brasil. Graduada
em ciências sociais
e doutora em
educação física
pela Universidade
Estadual de
Campinas (Unicamp).
Orcid: 0000-0003-
0926-7302.
<marianazuaneti@
gmail.com>.
*** Vitor Vasquez
é graduado em
ciências sociais
e doutor em
ciência política
pela Universidade
Estadual de
Campinas (Unicamp),
Campinas, São
Paulo, Brasil; \\ ** Mariana \\ Zuaneti Martins é \\ da Universidade \\ Federal do Espírito \\ Santo (Ufes), Vitória, \\ spírito Santo, \\ em ciências sociais \\ e doutora em \\ educação física \\ Estadual de \\ Campinas (Unicamp). \\ Orcid: 0000-0003 \\ 0926-7302. \\ <marianazuaneti@ \\ $* * *$ Vitor Vasquez \\ é graduado em \\ ciências sociais \\ e doutor em \\ cia política \\ Estadual de \\ Campinas, São
}


membro do Centro Brasileiro de Análise e Planejamento (Cebrap). Orcid: 0000-00028334-3548. <vitor.vasquez@ gmail.com>.

1. A Lei 8.672, de 1993, conhecida como Lei Zico (Brasil, 1993), concebeu uma organização ao esporte profissional no país, além de materializar o reconhecimento do esporte como direito social e dever do Estado. Por meio do esporte participação e do esporte educaciona e com a criação do Fundo Nacional de Desenvolvimento Desportivo (Fundesp), esta legislação ofereceu perspectivas de financiamento de programas de inclusão social via prática esportiva com benefícios fiscais específicos (Carvalho, 2013). Em 1995, criou-se o Instituto Nacional de Desenvolvimento do Desporto (Indesp), cujo objetivo era promover e desenvolver a prática do esporte, fomentando algumas políticas públicas de esporte e lazer como o Programa Esporte Solidário, que originou o Programa Segundo Tempo, em 2004 (Tubino, 2010). Em 1998, aprovou-se a Lei 9.615, a Lei Pelé, principal legislação infraconstitucional atual que regula e descreve o financiamento e o

\section{Introdução}

No Brasil, o Estado exerce papel central na regulação da política esportiva (Linhales, 1996; Starepravo \& Marchi Júnior, 2016), promovendo as principais ações sobre a questão. A Constituição Federal de 1988, que estabeleceu o direito ao esporte e lazer e a autonomia das entidades que fomentavam a prática esportiva, desencadeou uma série de demandas ao poder público (Athayde, 2011). Como resultado, diversas legislações esportivas infraconstitucional emergiram a partir da década de $1990^{1}$.

O Poder Executivo é fundamental nessa dinâmica, conforme demonstram pesquisas que se debruçam sobre a trama documental, normativa e jurídico-institucional da política esportiva brasileira (Starepravo \& Marchi Júnior, 2015). Contudo, de acordo com alguns estudos de revisão sobre a produção acadêmica em políticas públicas de esporte e lazer no Brasil, a atuação de outros atores tem sido ofuscada nessa agenda investigativa (Amaral \& Pereira, 2009; Amaral, Ribeiro \& Silva, 2014). Além disso, as poucas pesquisas que consideram a arena política de maneira mais ampla, lançaram luz sobre a participação da sociedade civil no processo decisório (Amaral, 2005; Areias \& Borges, 2011; Castelan, 2011; Stigger, 1998).

Esse panorama indica uma lacuna no que se refere ao papel do Congresso brasileiro na construção da política esportiva. Mesmo reconhecendo a preponderância do Poder Executivo na formulação dessas legislações ou programas (Mascarenhas, 2016; Ribeiro et alii, 2017), pouco se sabe quanto à participação do Poder Legislativo nesse processo. A organização dos megaeventos esportivos no Brasil trouxe algum interesse nessa temática, em especial sobre a discussão, aprovação e conteúdo da Lei Geral da Copa (Bomfim, 2012; Reis, 2012; Silva, Martins \& Amaral, 2016). Essa situação não é particular ao caso brasileiro. Em outros países, uma série de investigações tem se debruçado sobre os processos políticos que incluem o teor e a aprovação de legislações específicas para acolhimento dos megaeventos esportivos (Horne, 2017; Horne \& Manzenreiter, 2006; Vigor, Mean \& Tim, 2004).

Contudo, à exceção da discussão específica sobre a legislação dos megaeventos, no Brasil, o Poder Legislativo é descrito na conformação das políticas públicas esportivas apenas em casos pontuais. Em um desse estudos, referente à Lei Pelé, delineou-se as relações entre os campos político e esportivo (Hirata \& Freitas Júnior, 2014). Em outro, sobre a aprovação do Programa de Modernização da Gestão e de Responsabilidade Fiscal do Futebol Brasileiro (Profut), realizou-se um balanço de diferentes atores do processo político dessas legislações (Matias \& Mascarenhas, 2018). Há ainda uma investigação sobre a atuação da Frente Parlamentar do Futebol (Mendes \& Codato, 2015). 
O objetivo deste artigo é ajudar no preenchimento deste espaço. Para tanto, investigamos como a Câmara de Deputados, por meio da comissão permanente responsável pelo esporte, se especializa e se organiza a fim de participar do resultado final das políticas públicas esportivas.

A lacuna apresentada ignora a relevância do Legislativo no processo político brasileiro. Ainda que o Executivo inicie a maior parte dos projetos de lei aprovados (Figueiredo \& Limongi, 1996; 2001; Limongi \& Figueiredo, 2009; Pereira \& Mueller, 2000), sabe-se que a Câmara dos Deputados, por meio das comissões, participa do processo legislativo. As comissões servem como instrumento de controle dos partidos membros da coalizão, nas quais atuam monitorando as propostas de seus pares, iniciadas nos ministérios cuja temática corresponde à sua comissão (Inácio \& Rezende, 2015). Operam ainda como instrumento da oposição para controlar e monitorar o governo, gerando informação ao plenário sobre projetos iniciados pela coalizão governista (Santos \& Almeida, 2011). Por fim, destaca-se o papel fundamental dos relatores dos projetos de lei, na análise e modificação de propostas que as comissões escrutinam (Freitas, 2016a). Tal relevância do sistema de comissões demanda que - ao se investigar a elaboração, discussão e aprovação de políticas públicas sobre uma área específica - se observe ainda o trabalho desenvolvido pela comissão permanente responsável pelo tema.

As comissões permanentes da Câmara dos Deputados conformam um dos lócus institucionais de tomada de decisão na elaboração de política pública no Brasil. Composta por deputados federais, cada comissão trata especificamente de sua jurisdição, tendendo a ser, portanto, especialista em sua área temática. Especialização é um atributo caro de se adquirir, pois requer recursos como tempo e qualificação. Assim, quanto mais específica é a jurisdição de uma comissão, maior facilidade esta tem para direcionar a utilização destes recursos em busca de expertise. No caso do esporte, de 2003 a 2014, a temática foi tratada na Comissão de Turismo e Desporto (CTD), acumulando duas competências num só órgão. No entanto, desde 2014, a comissão foi desmembrada, gerando uma específica somente para a área, a Comissão do Esporte (Cespo)².

A fim de compreender os efeitos do desmembramento da CTD na atuação da comissão responsável pelo esporte, verificamos em que medida os atores ${ }^{3}$ e suas atuações modificaram-se com a criação da Cespo. Para tanto, mobilizamos as comissões responsáveis pela jurisdição esportiva entre 2003 e 2018. Como a atuação de partidos e deputados no Legislativo ocorre principalmente nestes órgãos, nossa escolha permite investigar com detalhes os atores políticos interessados em política esportiva nesta arena, fornecendo um desenho acurado das preferências ali presentes. Comparamos os perfis de atores e suas atuações na CTD em relação à Cespo pois, dado o ganho de funcionamento do esporte no Brasil (Veronez, 2007).

2. Até 2003, a temática do esporte estava diluída junto à comissão de educação. Em 1989, na Comissão de Educação, Cultura, Esporte e Turismo; em 1990, na Comissão de Educação, Cultura e Desporto, onde permaneceu até 2003.

3. Ao longo do texto, damos prioridade ao termo ator para identificar quem age na comissão. Em última instância, quem atua são os deputados federais, contudo, eles não agem de forma independente, pois são constrangidos por suas lideranças partidárias (Cox \& McCubbin, 1993), pelo plenário como um todo (Krehbiel, 1992) e/ou por seus eleitores (Mayhew, 1974). Esses constrangimentos são, por vezes, conflitantes entre si e não é objeto deste artigo investigar qual prevalece em qual circunstância. Por não identificarmos quem é o principal dos deputados em cada caso, optamos pelo o termo ator. 
especificidade da última, buscamos demonstrar que houve um incremento de especialização por parte da comissão e dos envolvidos em termos de política esportiva.

Argumentamos que a existência de uma comissão exclusiva sobre esporte aumentou o grau de especialização sobre o tema no Legislativo, tornando este poder mais atuante nas políticas desenvolvidas na área. A partir disso, o desmembramento da CTD e a criação da Cespo gerou um maior interesse tanto da coalizão governista como da oposição na composição dessa comissão, quando comparamos as duas. Isso se demonstrou tanto em termos de composição partidária como em atividade legislativa, o que foi observado pela comparação da distribuição de relatoria quando o presidente da comissão era da coalizão ou da oposição. Além disso, a criação da Cespo fez com que a comissão participasse mais do conteúdo final dos projetos, alterando-os com maior frequência e intensidade. Finalmente, observou-se uma maior quantidade de projetos apreciados, bem como uma maior diversificação temática, sugerindo que a especialização da comissão tornou deputados e partidos mais sensíveis à necessidade de proposição e aprovação de distintas matérias relacionadas ao esporte.

Os resultados demonstram que a temática esportiva tem se pronunciado com mais relevância no Poder Legislativo, a partir da criação da Cespo. Este padrão foi desencadeado quando o país se preparava para sediar os megaeventos esportivos, em resultado da demanda de política pública e legislação para tal. Contudo, as relevantes alterações institucionais promovidas - como a criação de uma comissão específica no âmbito da Câmara dos Deputados - gerou consequências que extrapolaram as justificativas iniciais. Por isso, passado o período de realização dos megaeventos, a Cespo permanece como legado institucional do processo, atuando de forma mais frequente e eficiente.

\section{O esporte}

\section{nas comissões permanentes}

O atual sistema de comissões foi estabelecido pela Constituição de 1988. Essencialmente, é composto por comissões permanentes que, cada qual em sua temática, analisam, modificam e aprovam ou rejeitam os projetos de lei que tramitam pelo Legislativo. Segundo o Regimento Interno da Câmara dos Deputados, as comissões também podem solicitar audiências públicas, convocar ministros e outras autoridades, reivindicar ajuda especializada do corpo técnico do Legislativo etc. A forma como o sistema se organiza não é estática, o que pode ser observado pelo crescente número de comissões ao longo dos anos, pelas alterações na quantidade de deputados nomeados para cada órgão e pela inclusão, supressão ou desagregação de competência que compõe uma mesma comissão (Vasquez \& de Freitas, 2019). 
Na esteira dessa dinâmica, foi criada, em fevereiro de 2014, por meio da Resolução no 54/2014 (Câmara dos Deputados, 2014a), a Cespo. A justificativa para o desmembramento consta do projeto de resolução da Câmara dos Deputados que originou a norma, o PRC 237/2014 (Câmara dos Deputados, 2014b). Segundo o texto, a separação visou atender às demandas geradas pelo aumento de volume e complexidade das propostas que a comissão passaria a apreciar naquele período, em função de o país sediar a Copa do Mundo de 2014 e as Olimpíadas de 2016. Neste cenário, as matérias analisadas exigiriam cada vez mais especialização e eficiência por parte da comissão e de seus membros.

Entretanto, uma vez alterado o status quo, os efeitos permaneceram no processo legislativo. Ou seja, o desmembramento temático possivelmente alterou no longo prazo - e não apenas durante a realização dos megaeventos - a forma como a Câmara passou a lidar com as políticas públicas sobre esporte e os incentivos oferecidos aos partidos e deputados para participarem da comissão responsável pela temática esportiva.

Mariana Martins e Vitor Vasquez (2018) apontaram indícios do ganho de especialização no tema do esporte promovido pela comissão entre 2014 e 2016, após a criação da Cespo. Desde então, houve significativo acréscimo na participação de deputados vinculados ao esporte, bem como aumentou o interesse dos partidos da coalizão governista nesta comissão. Essa alteração no perfil da comissão indica incentivos para que partidos e deputados nela atuem. Isso pode ter sido ocasionado pela organização dos megaeventos, que teria gerado uma demanda de especialização dos deputados na temática e o aumento de interesse por parte da coalizão. Além disso, Marcelo Teixeira e colaboradores (2018) demonstraram o crescimento do impacto dessa comissão durante o período do Plano Plurianual (PPA) de 20122015, no que diz respeito às emendas executadas sobre a temática esportiva. Por essa via, mapear o perfil desses atores, suas preferências e a forma como se organizam e atuam nas comissões é fundamental para melhor compreender o processo de produção de política pública esportiva.

\section{Universo analítico e modo} de interpretação dos resultados:

\section{CTD versus Cespo}

Para descrever o perfil dos atores e das atuações que permeiam a atividade legislativa sobre esporte, comparamos aspectos de composição das comissões - CTD e Cespo - e dos projetos de leis analisados, antes e após o desmembramento (20042013 e 2014-2018). Isso forneceu um panorama geral da influência do Legislativo 
4. Pesquisas sobre mudanças institucionais (Binder, 1995; Gomes, 2006; Immergut, 1992; Medeiros, 2013; North, 1990; Przeworski, 2004) comprovam a pertinência de se investigar alterações de regras - formais ou informais para uma melhor compreensão de processos políticos e resultados das políticas viabilizadas. na elaboração de política pública esportiva durante o período contemplado e permitiu demonstrar de que maneira o quadro foi alterado após a mudança institucional ${ }^{4}$ desencadeada pela criação da Cespo.

Em termos de atores, analisamos os padrões em relação à composição partidária e à definição dos principais membros da comissão, quais sejam, presidentes (Inácio \& Rezende, 2015) e relatores (Freitas, 2016a; Santos \& Almeida, 2011). Para tal, examinamos o total de deputados que compõe a comissão, o quanto a composição partidária é proporcional à composição observada no plenário e os padrões partidários de ocupação dos principais cargos. Por meio do número de membros, buscamos identificar se a comissão se tornou mais atrativa aos partidos e deputados após o desmembramento. A interpretação, nesse caso, é direta: quanto mais membros titulares, maior o incentivo existente à atuação na comissão.

Em relação à composição partidária, investigamos em que medida a comissão é proporcional ao plenário, antes e após a Cespo. Quanto mais proporcional, mais a comissão representa um microcosmo da Câmara dos Deputados (Krehbiel, 1992). Consequentemente, mais relevante esta tende a ser no sistema, pois mais partidos se interessam por sua jurisdição. Para medir o grau de proporção entre a comissão e a Câmara dos Deputados, mobilizamos o seguinte cálculo:

$I D P=\frac{\left[\sum_{i=1}^{n}\left|\left(\frac{\text { total membros partido }_{i} \text { Comissão }}{\text { total membros Comissão }}-\frac{\text { total membros partido } \text { Câmara }_{\text {âta }}}{\text { total membros Câmara }}\right)\right|\right]}{n}$

IDP: índice de desproporcionalidade partidária; $i: i^{\text {essimo }}$ partido com membro na comissão; $n$ : número de partidos com membro na comissão.

A ocupação de presidência de comissão e relatoria de projetos é o último aspecto em pauta que tange a dimensão dos atores envolvidos na produção de política esportiva no interior do Legislativo. Sobre este ponto, aferimos se houve aumento da atuação da coalizão governista nestes postos. Dada a preponderância do Executivo no processo legislativo brasileiro (Figueiredo \& Limongi, 2001; Pereira \& Mueller, 2000; Santos, 2002), uma maior participação da coalizão sugeriria um ganho de relevância do tema esportivo em termos de política pública. Para avaliar a atuação de presidentes e relatores nos projetos escrutinados pela comissão em termos de pertencimento ou não à coalizão governista, verificamos se, na data da designação do relator, o partido - do presidente e o do relator - ocupava algum ministério.

Do ponto de vista da atuação desses atores, descrevemos o trabalho na comissão quanto aos projetos de leis escrutinados. Isso foi possível a partir de informações sobre todas as designações de relatores para apreciação de matéria realizadas pelos 
presidentes ${ }^{5}$ entre 2003 e 2018. Quanto à designação dos relatores, analisamos se presidentes de comissão que pertencem à coalizão tendem a privilegiar relatores também do governo, e se o padrão anterior e posterior à criação da Cespo se alterou.

Além disso, investigamos a quantidade de projetos que tramitaram pela comissão, o teor das proposições, o resultado dos pareceres emitidos pelos relatores e o posicionamento da comissão em relação aos pareceres. Em relação às matérias escrutinadas, medimos se, dado o ganho em especialização a partir da criação da Cespo, houve aumento no número de projetos tramitados pela comissão.

Isto feito, testamos, a partir de uma regressão logística, a seguinte hipótese: quanto mais especializada for a comissão, maior será sua capacidade de escrutinar os projetos que analisa. Consequentemente, maior tende a ser sua interferência no conteúdo final da matéria. Ou seja, testamos se, dado o ganho de especialização gerado a partir da criação da Cespo, a comissão responsável pelo esporte passou a modificar mais as propostas escrutinadas em seu interior. Para tanto, elaboramos dois modelos. No primeiro, a variável dependente foi a proposição de alteração via emenda; no segundo, consideramos a alteração via substitutivo. Em ambos os casos a variável independente foi uma dummy, considerando 1 quando o projeto foi analisado pela Cespo, e 0 quando o escrutínio foi realizado pela CTD.

Por fim, no que diz respeito ao conteúdo do material analisado pela comissão, classificamos as matérias e comparamos seus conteúdos considerando a CTD e a Cespo. Para tanto, utilizamos a classificação da atividade esportiva contida na Lei Pelé (Brasil, 1998) ${ }^{6}$, exceto quando o projeto de lei é regulatório do sistema - que classificamos como sistema esportivo -, ou quando se trata do financiamento do esporte - que tratamos como a categoria financiamento. Essas duas classificações extras foram estabelecidas, pois abordam duas temáticas que são transversais às demais, mas bastante específicas. Neste aspecto, uma diversificação das temáticas abrangidas e um aumento proporcional no volume de matéria confirmariam o aumento no grau de especialização da comissão após desmembramento.

Para executar essa análise, montamos dois bancos de dados originais. O primeiro é composto de todos os membros titulares, seus partidos e os cargos que ocuparam na CTD e na Cespo - presidente, 1ㅇ vice-presidente, 2ㅇvice-presidente, 3ㅇvice-presidente e titular - entre 2003 e 2018. Essas informações foram obtidas no Banco de Dados Legislativos do Centro Brasileiro de Análise e Planejamento (Cebrap) e no sítio eletrônico da Câmara dos Deputados. O segundo é composto pelos projetos escrutinados pelas comissões responsáveis pela temática do esporte de 2003 a $2018^{7}$, por toda designação de relatoria à qual essas matérias foram submetidas,
5. Segundo o Regimento Interno da Câmara dos Deputados, o presidente da comissão tem a prerrogativa de designar o relator que apreciará cada matéria que passa pelo órgão sob sua responsabilidade.

6. Ou seja, esporte educacional, de formação, de participação ou de rendimento. Para mais detalhes sobre o escopo de cada um, consultar a Lei 9.615/1998.

7. No caso da CTD, consideramos apenas as matérias de temática esportiva, excluindo da análise projetos de conteúdo exclusivamente relacionado ao turismo. 
8. CTD disponível em: <https://www2. camara.leg.br/ atividade-legislativa/ comissoes/ comissoespermanentes/ ctur/documentos/ relatorios-deatividades > Acesso em: 01 Mar. 2019; e Cespo disponível em: <https://www2. camara.leg.br/ atividade-legislativa/ comissoes/

comissoespermanentes/ cespo/documentos/ relatorios?b start:int $=15>$. Acesso em: 01 Mar. 2019.

9. Como a composição das comissões é estabelecida no início de cada sessão legislativa, não consideramos 2003, 0 ano inaugural da CTD, iniciando nossas análises no ano de 2004. Nesse caso, a participação na comissão ficou a cargo dos membros das duas comissões exclusivas que a originaram: Comissão de Economia, Indústria, Comércio e Turismo e Comissão de Educação, Cultura e Desporto. A mesma lógica foi utilizada na análise de proporcionalidade partidária. pelos dados partidários dos relatores e pelo tipo de alteração proposto ao projeto, quando era o caso. Para esse banco, os relatórios anuais da CTD e da Cespo ${ }^{8}$, disponíveis no sítio eletrônico da Câmara dos Deputados, serviram como fonte.

\section{Atores interessados em política esportiva no Legislativo}

A primeira característica analisada em relação aos atores é o número de membros titulares que compõe as comissões responsáveis pela temática do esporte entre 2004 e 2018\%. Segundo o Regimento Interno da Câmara dos Deputados, cada comissão deve ter entre 3,5\% e 13\% dos deputados da Casa. Assim, embora haja uma restrição regimental, existe uma faixa considerável para que partidos e deputados atuem neste interstício. Além disso, existem comissões, via de regra as mais antigas, que demandam exclusividade dos deputados, sendo que cada um pode ser titular em apenas uma destas. Por outro lado, existem comissões cumulativas, nas quais os deputados podem participar de uma além daquela que lhe exige exclusividade (Vasquez \& de Freitas, 2019). A CTD e a Cespo são comissões cumulativas. Os dados referentes ao número de membros titulares por ano da comissão estão expostos no Gráfico 1.

\section{GRÁFICO 1}

FRAÇÃO DA CÂMARA DE DEPUTADOS TITULAR

DA COMISSÃO VINCULADA AO ESPORTE, 2004-2018

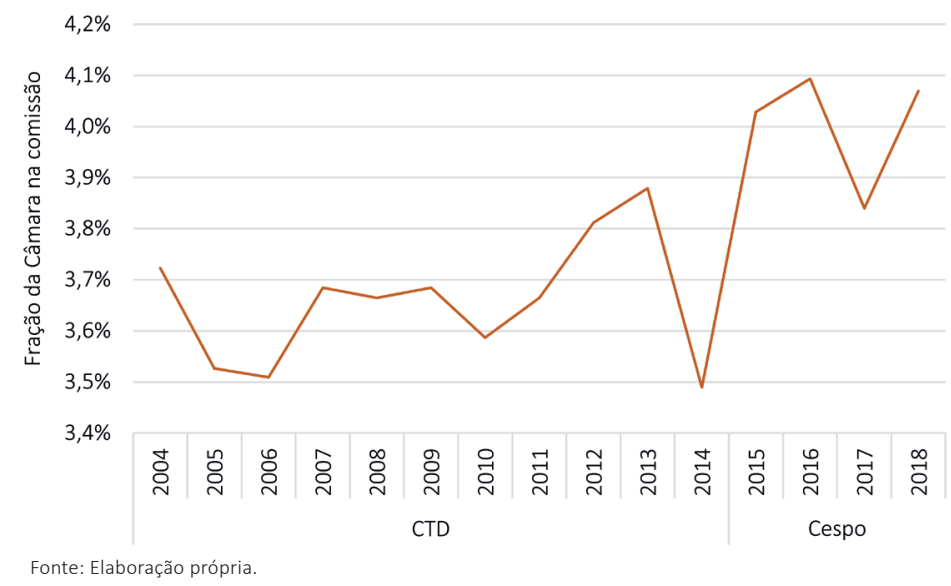

É possível observar que há incremento, ainda que suave, no número de deputados titulares da comissão vinculada ao esporte a partir de 2015, um ano após a criação da Cespo. Isso sugere um ganho, após o desmembramento, de interesse por esta comissão. Ao mesmo tempo, deve-se notar que o preenchimento da comissão durante todo o período ficou bem próximo ao mínimo estabelecido pelo Regimento 
Interno da Câmara dos Deputados, indicando que a temática não está entre as mais requisitadas da Casa Legislativa. Este comportamento é o padrão observado em praticamente todas as comissões cumulativas. A título de comparação, a média do percentual da câmara de deputados que integra uma comissão permanente no período foi de 3,9\% para aquelas comissões que podem ser cumulativas e 6,1\% para aquelas que são exclusivas (Vasquez \& de Freitas, 2019). Dado este contexto, o aumento no total de membros entre 2015 e 2018 deve ser ainda mais ressaltado.

Outro elemento que ajuda a compreender o grau de relevância da comissão é verificar o quanto sua composição partidária se aproxima da composição da Câmara dos Deputados. Neste sentido, o Gráfico 2 demonstra, ano a ano, o índice de desproporcionalidade partidária - apresentado na seção anterior - que a comissão apresenta, tomando como referência a Câmara dos Deputados como um todo ${ }^{10}$. Novamente comparamos a CTD com a Cespo.

GRÁFICO 2

ÍNDICE DE DESPROPORCIONALIDADE PARTIDÁRIA

DA COMISSÃO VINCULADA AO ESPORTE, 2004-2018

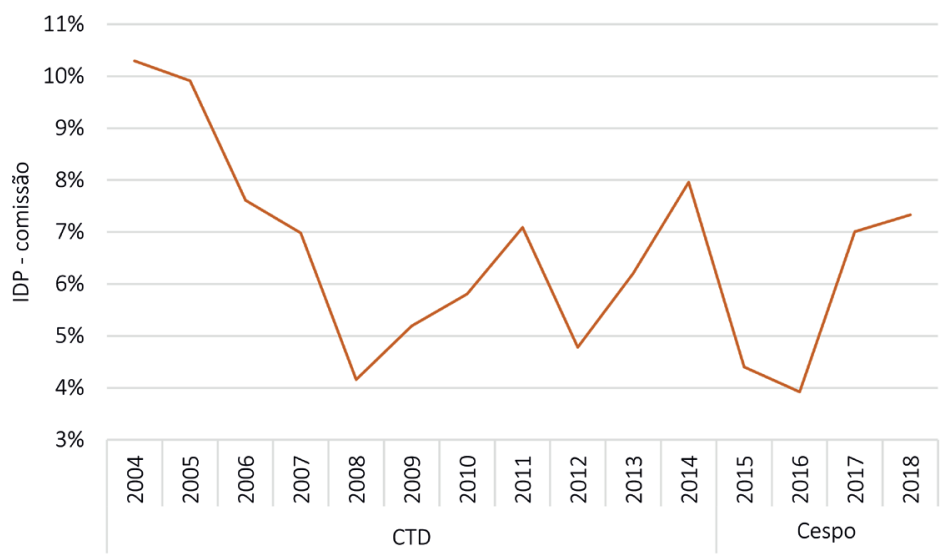

Fonte: Elaboração própria
10. Os dados foram estabelecidos mês a mês. A partir disto, calculamos a média anual.

Nossos resultados demonstram uma certa variação em termos de índice de desproporcionalidade partidária antes e após a Cespo. Contudo, duas informações são relevantes. Em primeiro lugar, chama atenção a diminuição da desproporcionalidade a partir de 2006-2007, pois os valores dos primeiros anos de CTD, 2004 e 2005, eram muito elevados. Essa mudança pode estar relacionada à escolha do Brasil como sede da Copa do Mundo de 2014, o que impulsionou uma série de mudanças na legislação. Além disso, 2007 foi o ano dos Jogos Pan-americanos do Rio de Janeiro. Estes dois fatores ajudam a justificar esse direcionamento dos esforços 
legislativos em relação à política esportiva (Mascarenhas et alii, 2012; Matias \& Mascarenhas, 2017). Em segundo, destacamos que os anos de índices de desproporcionalidade partidária mais baixos da série - quando a comissão mais representou um microcosmo do plenário em termos partidários - são 2015 e 2016, período entre a Copa do Mundo e os Jogos Olímpicos. Isso preconiza uma atenção maior ao tema durante os megaeventos, mas também um certo arrefecimento após suas realizações, pelo menos neste aspecto em tela.

O primeiro gráfico indica que, comparada à CTD, a Cespo é uma comissão mais atrativa, devido ao aumento no número de membros. No entanto, quanto ao índice de desproporcionalidade partidária, exposto no segundo gráfico, os dados não ratificam esta situação, ainda que exista uma queda neste índice no período dos megaeventos esportivos. Isto aponta para dois caminhos. Por um lado, para o ganho de relevância que a temática esportiva pode ter adquirido a partir de uma comissão que cuida exclusivamente do tema; por outro, para a cautela que devemos ter ao se formular conclusões nesse sentido, dado o ainda curto período de existência da Cespo.

Contudo, o interesse dos atores políticos na comissão vinculada ao esporte pode se expressar de outra maneira: por meio do preenchimento de cargos estratégicos. A partir disso, para aferir se houve maior interesse por parte da coalizão nestas comissões, elaboramos o Gráfico 3, no qual apresentamos, separada entre CTD e Cespo, a porcentagem de vezes em que um presidente da comissão, integrante da coalizão, distribuiu matérias a serem relatadas, e de ocasiões nas quais

GRÁFICO 3

PRESIDENTES INTEGRANTES DA COALIZÃO DISTRIBUINDO PROJETOS; RELATORES DESIGNADOS, CTD E CESPO

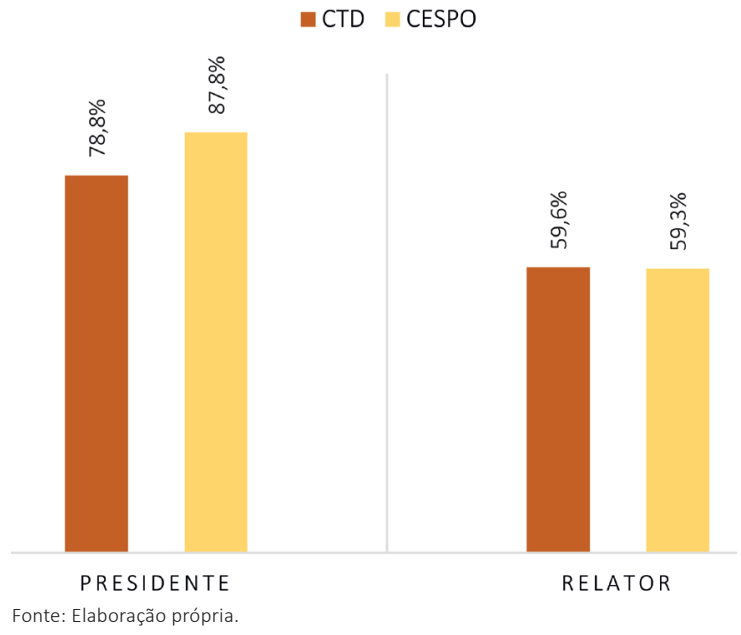


relatores, integrantes do governo, foram designados para emitirem parecer sobre os projetos.

Como é possível observar, a proporção de distribuição de matérias feita por presidentes da coalizão foi ampliada em 9\% comparando a CTD com a Cespo, sugerindo uma maior atuação do governo na comissão e, portanto, uma maior preocupação com a temática esportiva. No entanto, o aumento de participação de presidentes da coalizão não ocorreu em paralelo a um ganho proporcional de relatores do governo designados para emitir parecer sobre as matérias que tramitaram na comissão. Esta é uma informação relevante, pois, como destaca Andréa Freitas (2016a), relatores são atores essenciais no Legislativo, dada sua capacidade de alterar as matérias que analisa. Mas por que isto não ocorreu? Por que a maior participação de presidentes da coalizão não se correlacionou a um ganho de atuação de relatores também da coalizão? Para responder a estas questões, analisamos como os atores anteriormente descritos operam na comissão.

\section{Atuação dos entes políticos no interior da comissão responsável pelo tema do esporte}

O primeiro passo para investigar a atuação dos atores políticos nas comissões em foco é compreender em que medida a estagnação da atuação de relatores da coalizão foi responsabilidade do governo. Para tanto, elaboramos o Gráfico 4, no qual exibimos, comparando CTD e Cespo, os seguintes padrões complementares de de-

GRÁFICO 4

Designação: Presidente/ Relator, CoAlizÃo/ OposiçÃo, CTD e Cespo

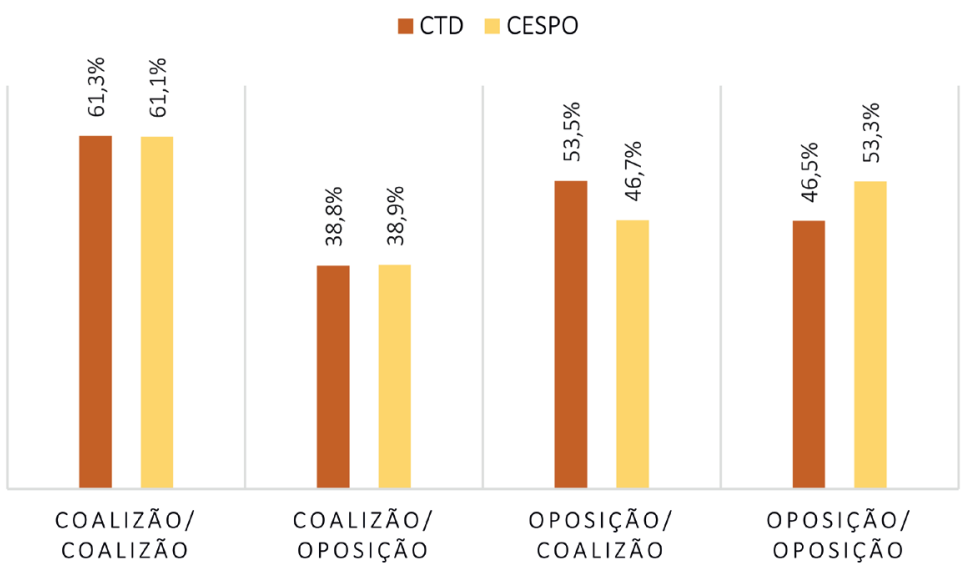

Fonte: Elaboração própria

PRESIDENTE/ RELATOR 
signação de relatoria: presidente coalizão/relator coalizão; presidente coalizão/ relator oposição; presidente oposição/relator coalizão; e presidente oposição/relator oposição.

O perfil exibido pelo Gráfico 4 é interessante, pois mostra que o resultado exposto no gráfico anterior se deve muito mais a uma atuação da oposição do que do governo. Os presidentes da coalizão mantiveram porcentagens muito semelhantes de distribuição de relatoria na CTD e na Cespo. Porém, presidentes da oposição reduziram a designação de relatores da coalizão, em prol da própria oposição. Este resultado ajuda a ratificar a importância do Legislativo como lócus de tomada de decisão política e o ganho de relevância da temática esportiva para os atores parlamentares como um todo. Afinal, a coalizão buscou aumentar sua atuação na comissão após o desmembramento, com seus presidentes distribuindo uma porcentagem de matéria esportiva superior ao que se observava na CTD. Entretanto, a oposição também agiu, reduzindo a proporção de designações feitas a relatores do governo.

A fim de compreender as razões desta possível disputa entre governo e oposição na CTD e na Cespo, propomos um aprofundamento nos trabalhos desenvolvidos no interior do órgão. Se este maior interesse dos atores políticos na Cespo se relaciona aos ganhos que a comissão obteve - em termos de recursos e de especialização - ao se desmembrar da temática do turismo, os padrões observados até então devem se refletir em termos de conteúdo. Dado o aumento de incentivo aos atores políticos envolvidos, espera-se que a atividade legislativa desenvolvida por esta comissão também se incremente (Martin, 2014; Mattson \& Strøm, 1995; Strøm, 1990). Sobre este aspecto, começamos por investigar o volume de trabalho realizado no interior da comissão. Para tanto, comparamos, a partir do Gráfico 5, a quantidade de pareceres votados considerando a CTD e a Cespo.

Sobre este gráfico, três fatores precisam ser sublinhados. Em primeiro lugar, o aumento no total de pareceres votados pela comissão ocorreu já em 2013. Isto corrobora a relevância dos megaeventos esportivos no processo político aqui investigado, ratificando a justificativa apresentada pelos deputados para a necessidade de desmembramento da CTD. Em segundo lugar, sublinhamos a baixa atividade legislativa da comissão em 2016. Tal redução está associada ao processo de impeachment da presidente Dilma Rousseff que ocorreu naquele ano, mas que teve início em 2 de dezembro de 2015 (Agência Senado, 2016). Como divulgado pelo próprio presidente em exercício da Casa, o processo afetaria bruscamente a atividade das comissões permanentes (Calgaro \& Passarinho, 2016). Em terceiro lugar, os padrões mais altos de atividade legislativa se mantiveram em 2017 e 2018, ou seja, mesmo após a realização dos megaeventos. Isto é, em termos de atividade legislativa, a alteração do 


\section{GRÁFICO 5}

TOTAL DE PARECERES VOTADOS NA COMISSÃO -

CTD E CESPO, 2003-2018

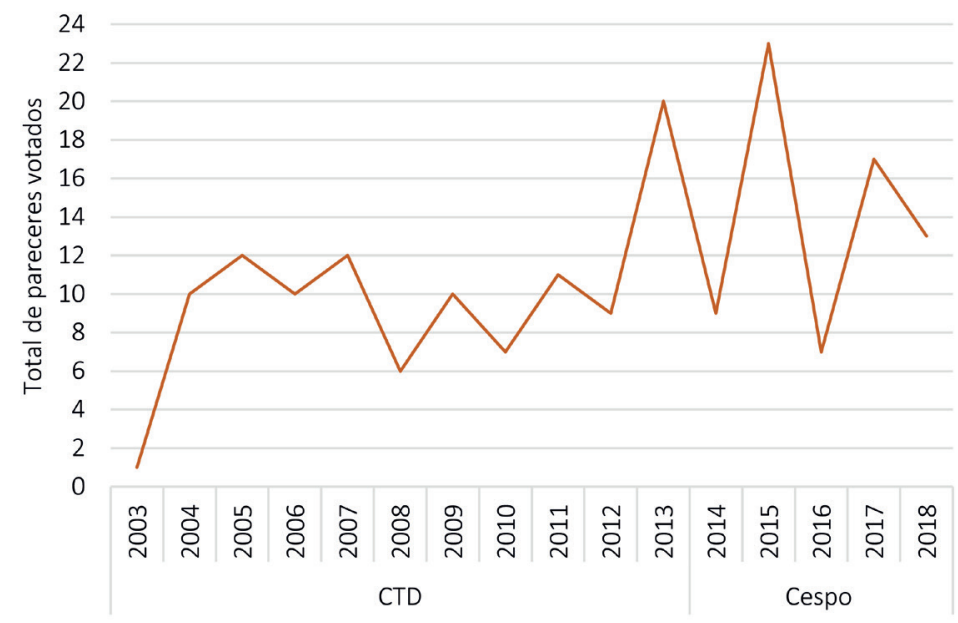

Fonte: Elaboração própria.

status quo promovida pelo desmembramento da comissão esporte manteve seus efeitos, mesmo após a realização dos eventos que justificaram tal ação.

Contudo, além da capacidade de emitir pareceres sobre propostas, deve-se analisar se o tipo de parecer se alterou após a criação da Cespo. Afinal, espera-se que o ganho de especialização gerado a partir do desmembramento forje uma maior expertise da comissão sobre a temática esportiva e, por conseguinte, uma maior interferência nos projetos analisados. Os relatores podem propor dois tipos de alteração ao projeto, emenda ou substitutivo. Foram testados dois modelos de regressão logística para medir o tipo de interferência da comissão no projeto analisado. Nas duas situações consideramos as 250 vezes em que um relator emitiu algum parecer na CTD ou na Cespo entre 2003 e 2018. A seguir, apresentamos a tabela com os dados da regressão. E, para melhor ilustração, sistematizamos os resultados, a partir de razão de chances, na figura após a tabela. As variáveis do teste foram estabelecidas da seguinte forma:

- Variável Dependente (modelo 1) - 1 se apresentou emenda; 0 se não apresentou;

- Variável Dependente (modelo 2) - 1 se apresentou substitutivo; 0 se não apresentou;

- Variável Independente (modelos 1 e 2) - 1 se Cespo e 0 se CTD. 
TABELA 1

REGRESSÃO LOGÍSTICA

Proposta de alteração de projeto: Cespo vs. CTD

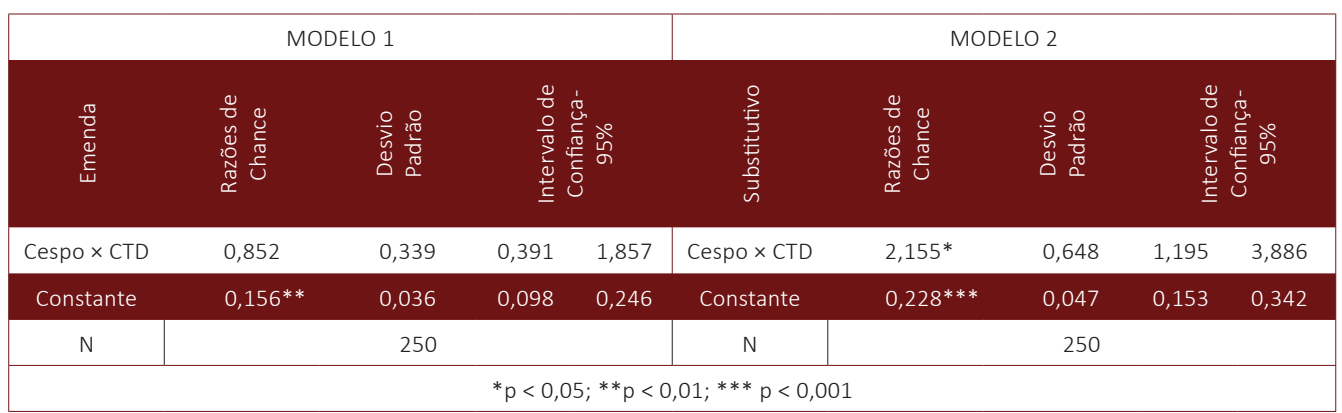

Fonte: Elaboração própria a partir do software Stata ${ }^{\oplus}$.

FIGURA 1

CESPO $\times$ CTD (2003-2018):

RAZÕES DE CHANCE PROPOSTA DE ALTERAÇÃO
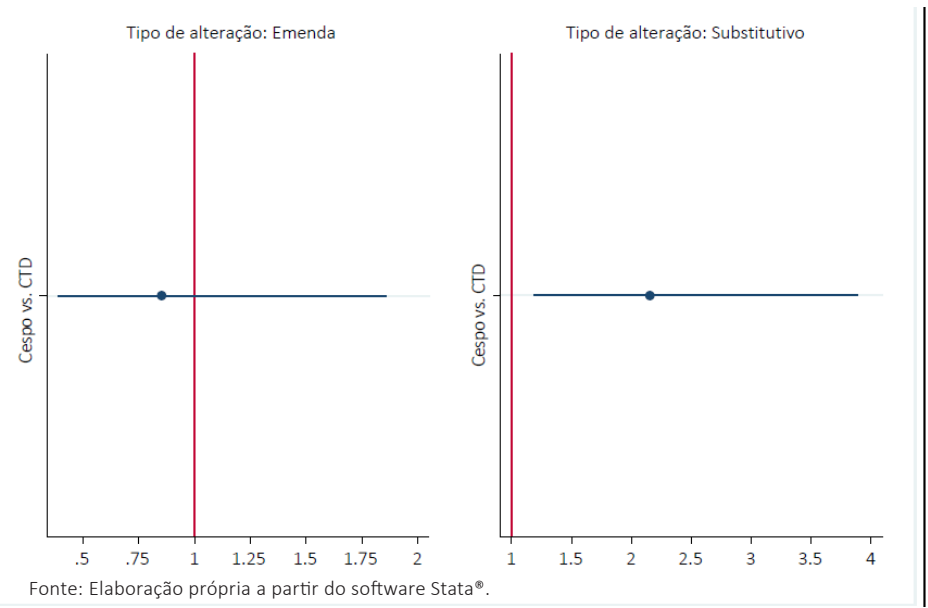

De acordo com o modelo 1, a chance de alteração via emenda a partir da Cespo é inferior quando comparada à CTD. Isso tenderia a contrariar nossa hipótese de especialização, não fossem duas considerações. Em primeiro lugar, deve-se notar que o modelo é bastante inconclusivo quanto ao seu resultado. Ao considerar uma significância estatística de $95 \%$, a chance de um relator da Cespo propor uma emenda a um projeto escrutinado varia de 0,39 a 1,86 vezes em relação à chance de um relator da CTD. Isto é, a probabilidade varia de menos da metade para quase duas vezes, tornando a interpretação de seu coeficiente, que gera a razão de chance, bastante imprecisa. Além disso, conforme destaca Freitas (2016b), a própria interpretação de alteração a partir da presença ou não de emendas pode ser problemática. De acordo com a autora: 
Uma emenda pode alterar um projeto de lei um pouco ou fazer alterações significativas. Uma emenda modificadora, por exemplo, pode fazer apenas pequenas alterações no texto sem, no entanto, alterar o significado do que está sendo proposto, ou seja, sem alterá-lo de fato. Uma emenda é uma unidade que não permite comparação e não mede o que se deseja medir; isto é, o quanto o projeto original é alterado (Freitas, 2016b: 10, nossa tradução) ${ }^{11}$.

Entretanto, ao tomarmos o modelo 2 como referência, tendemos a confirmar a nossa hipótese, tanto do ponto de vista estatístico, quanto na qualidade de nossa variável dependente enquanto indicador de alteração de projeto. Nesse sentido, a razão de chance de um relator da Cespo propor um substitutivo é 2,16 vezes a chance de o mesmo acontecer quando o relator atuava na CTD. Tal resultado apresenta significância estatística considerando um intervalo de confiança de 95\%. Além disso, o substitutivo ${ }^{12}$, como o próprio nome diz, substitui completamente o texto original por outra proposta. Consequentemente, as alterações propostas por este tipo de modificação tendem a ser mais substantivas. Em outras palavras, o resultado apresentado pelo modelo 2 tende a confirmar a hipótese de que a criação da Cespo, por tornar esta comissão especialista em uma só temática, aumentou a sua expertise e capacidade em lidar com a jurisdição esportiva, se comparada com a comissão anterior.

Uma vez que houve aumento no volume e na especialização da atividade legislativa com a criação da Cespo, resta analisar se ocorreu transformação também no perfil de proposta escrutinada pela comissão. Para tanto, classificamos as matérias segundo as categorias embasadas na Lei 9.615, de 24 de março de 1998, popularmente conhecida como Lei Pelé (Brasil, 1998). Além destas, outras duas categorias foram estabelecidas: financiamento e sistema esportivo. Assim, no Gráfico 6 estão expostas, por ano e por comissão, as proposições analisadas. Neste caso, consideramos todo projeto que tramitou nas comissões vinculadas ao esporte entre 2003 e 2018, mesmo aqueles que não tiveram o parecer votado.

O Gráfico 6 demonstra a preferência temática dos deputados em todo o período estudado. Ao ratificar o que outras pesquisas já anunciavam (Mascarenhas et alii, 2012; Starepravo \& Marchi Júnior, 2016; Teixeira et alii, 2018), sobretudo, no contexto que antecedeu os megaeventos esportivos, existe uma hipertrofia das proposições relacionadas ao esporte de alto rendimento, representando aproximadamente metade das proposições tramitadas. Em seguida, aparecem financiamento e sistema esportivo que, embora tenham sido destacados como categorias específicas por serem mais amplos que alto rendimento, têm intersecção com essa classificação, pois podem tratar da regulação de confederações e de políticas de incentivo ao esporte em todos os níveis, além de negociarem as dívidas dos clubes
11. No original:

"An amendment may change a bill a little bit or it can make significant changes. A modifying amendment, for example, may make only small changes in the text without, however, changing the meaning of what is being proposed, that is, without changing it in fact. An amendment is a unit that does not allow comparison and does not measure what one wants to measure; that is, how much the original bill is changed" (Freitas, 2016b, p. 10).

12. Segundo a página eletrônica da Câmara dos Deputados, substitutivo é uma "espécie de emenda que altera a proposta em seu conjunto, substancial ou formalmente. Recebe esse nome porque substitui o projeto. O substitutivo é apresentado pelo relator e tem preferência na votação, mas pode ser rejeitado em favor do projeto original" (Câmara dos Deputados, s/d). 
GRÁFICO 6

DISTRIBUIÇÃO DAS TEMÁTICAS DOS PROJETOS POR ANO, CTD E CESPO

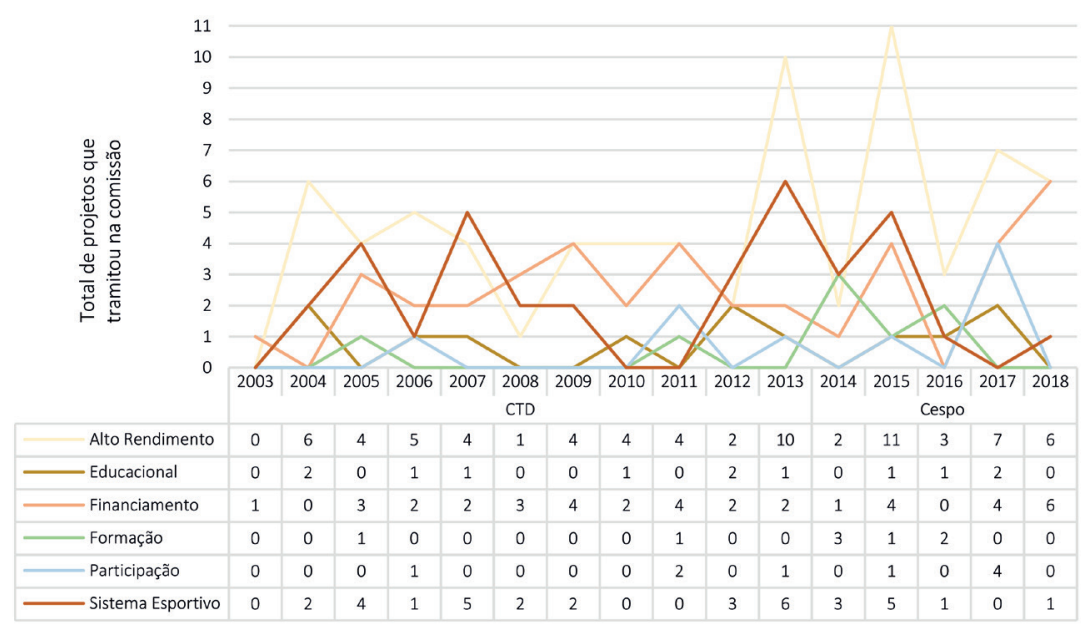

Fonte: Elaboração própria.

de futebol. Por fim, as classificações que se direcionam diretamente às questões do esporte e lazer enquanto direito - educacional, formação e participação - representam os menores números de matéria tramitada na comissão, estando sempre em valores inferiores quando comparadas às demais categorias.

No entanto, para além da prevalência do alto rendimento, chama atenção a maior frequência das proposições sobre outras temáticas quando comparamos a Cespo com a CTD. A maior presença de projetos de participação e sistema esportivo, por exemplo, indicam uma maior diversificação da atividade legislativa em relação às políticas públicas de esporte e lazer. Isto pode estar atrelado à atuação desta comissão com proposição e aprovação de emendas parlamentares que compuseram cerca da metade das emendas liquidadas destinadas ao orçamento do Ministério do Esporte entre 2012 e 2015 (Teixeira et alii, 2018). Tal qual notamos nas temáticas, nas emendas orçamentárias houve um aumento da densidade daquelas direcionadas ao esporte educacional e de participação, o que sugere também uma maior diversificação neste âmbito da atividade legislativa.

Nesse sentido, por mais que o aumento de atividade legislativa tenha sido incentivado pela organização dos megaeventos no país, foi acompanhado de uma diversificação das temáticas dos projetos apreciados. Isso ocorreu sobretudo a partir da 54ạ legislatura (2011-2014) e pode estar relacionado à consolidação dos programas vinculados à Secretaria Nacional de Educação, Esporte, Lazer e Inclusão 
Social, como o Programa Segundo Tempo e o Programa Esporte e Lazer da Cidade. Todavia, esse perfil declinou no ano de $2018^{13}$, alertando que pode ser prematuro tomar conclusões relacionando a emergência dessas temáticas à criação da Cespo.

Finalmente, no intuito de aprimorar a compreensão em torno da preferência política na comissão vinculada ao esporte, observamos em que medida os pareceres dos relatores são favoráveis ou contrários às proposições escrutinadas, separando essas informações por temática e entre CTD e Cespo. Tomamos a opinião do relator como indicativo da preferência da comissão enquanto órgão coletivo pois, durante toda a série investigada, somente em duas ocasiões os membros rejeitaram o parecer oferecido ${ }^{14}$.

GRÁFICO 7

PARECERES FAVORÁVEIS OU CONTRÁRIOS

ÀS MATÉRIAS ESCRUTINADAS: CTD × CESPO, 2003-2018

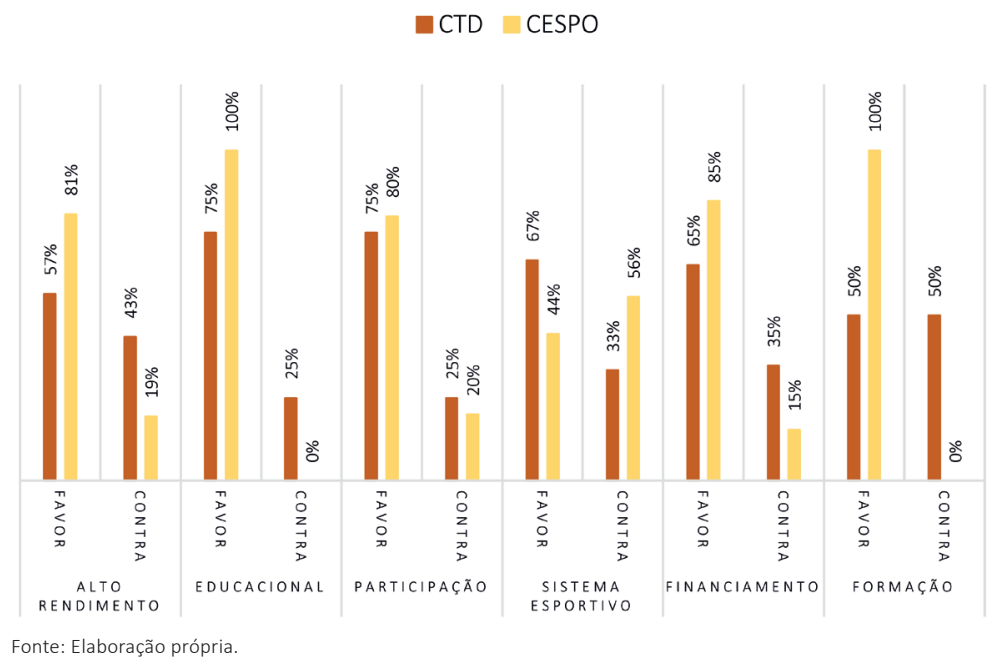

$\mathrm{Na}$ Cespo, apenas as matérias acerca do sistema esportivo foram mais rejeitadas que na CTD. No mais, notou-se um esforço dos atores políticos envolvidos na temática esportiva em relação à aprovação das matérias na Cespo, o que pode ser fruto de um ganho de especialização da comissão após o desmembramento. Afinal, como demonstrado, este ganho de expertise tornou os atores mais aptos a modificar o conteúdo das matérias escrutinadas em prol de suas preferências, o que aumenta a chance de que relatores sejam favoráveis ao teor final das proposições. Além disso, o aumento de interesse de partidos e deputados pela temática e sua especialização tendem a refletir em proposições mais bem elaboradas, o que também justificaria a redução de pareceres contrários às matérias analisadas. Entretanto, para ratificar

13. Cabe, todavia, ressaltar que a diminuição da atividade em ano de eleições federais parece ser uma constante durante $o$ período analisado.

14. Isto ocorreu
com o parecer
emitido pelo
deputado Asdrubal
Bentes, do PMDB/
PA, pela rejeição
do PL 5351/2013
(Brasil, 2013a)
(alto rendimento).
A comissão votou
contra o parecer em
julho de 2013. O
mesmo aconteceu
em março de 2013
com a opinião do
relator Valadares
Filho PSB/SE, cujo
parecer era favorável
ao PL 6700/2013
(Brasil, 2013b)
(sistema esportivo).
Para essa etapa
da análise, não
incluímos estes
pareceres rejeitados
pela comissão.
pela comissão. 
estas hipóteses, uma análise mais acurada sobre o conteúdo das matérias, bem como da justificativa dos pareceres favoráveis e contrários, seriam necessárias.

\section{Considerações finais}

Ao considerar o Poder Legislativo como um importante lócus de tomada de decisões sobre políticas públicas, em particular o sistema de comissões, argumentamos que o ganho de especialização obtido com a criação da Cespo contribuiu para que a temática esportiva ganhasse proeminência no processo legislativo brasileiro, em especial neste âmbito. Embora esse ganho possa ter relação com a organização dos megaeventos esportivos no país, o desmembramento de CTD e a criação da Cespo geraram mudanças de padrões de atuação legislativa com relação ao esporte cujos efeitos não se circunscrevem apenas a esse período.

Em termos de atores, destacamos a quantidade de deputados integrantes da Cespo. A proporção de deputados que compõem a comissão, em relação à Câmara, subiu após o desmembramento, e não caiu mesmo após os megaeventos esportivos, o que demonstra um maior interesse em fazer parte da Cespo quando comparado à CTD. Além disso, chama atenção o interesse de partidos do governo e da oposição na comissão, aferido por uma maior coordenação entre presidente e relator na distribuição de matérias. Sobre este aspecto, destaca-se a articulação da oposição, cujos presidentes passaram a distribuir cada vez mais relatorias a deputados também de partidos oposicionistas.

No que diz respeito às atividades da comissão, demonstramos que o total de proposições apreciadas aumentou com a criação da Cespo e continuou elevada, mesmo após o período dos megaeventos esportivos. Mais importante, apontamos que para além de um maior número de matérias escrutinadas, cresceu também o grau de interferência da comissão nesse processo, pois há um aumento importante de substitutivos apresentados pelos relatores às propostas examinadas. Isto ganha impacto, se observarmos que praticamente todas as decisões dos relatores foram ratificadas pelo coletivo da comissão durante o período analisado. Por fim, quanto às temáticas tratadas, as mesmas se diversificaram, em relação ao período anterior, e assim permaneceram durante toda a 55a legislatura. Assim, a partir da atuação dos atores envolvidos na comissão responsável pelo esporte, reforçamos o argumento de que houve ganho de especialização com a criação da Cespo e que o mesmo não se restringiu aos anos impactados pelos megaeventos esportivos.

Por outro lado, nossa pesquisa apresenta o seguinte limite: o pequeno período de existência da Cespo, que restringiu nossa análise sobre esta comissão a apenas uma 
legislatura. Diante disto, algumas frentes de pesquisa se abrem. Seria interessante uma comparação dos padrões da CTD/Cespo com outras comissões temáticas, a fim de evidenciar se esse ganho de especialização é exclusivo à Cespo ou se é um ganho do sistema de comissões. Outro desdobramento diz respeito a um estudo mais aprofundado acerca da atuação específica da CTD/Cespo nas proposições legais, porque esse é um importante indicativo das preferências políticas dos atores que atuam no Legislativo. Finalmente, a exploração de outras atividades da comissão - como a participação desta no orçamento, que já foi levantada por outras pesquisas, ou mesmo a proposição de audiências públicas - contribuiriam para ter uma compreensão mais ampla sobre a atuação da Câmara dos Deputados sobre a política pública esportiva.

\section{Referências}

AGÊNCIA SENADO. Impeachment de Dilma Rousseff marca ano de 2016 no Congresso e no Brasil. Brasília: Senado Federal, 28 Dez. 2016. Disponível em: <https:// www12.senado.leg.br/noticias/materias/2016/12/28/impeachment-de-dilma-rousseff-marca-ano-de-2016-no-congresso-e-no-brasil>. Acesso em: 02 Abr. 2019.

AMARAL, Silvia Cristina Franco. Avanços e contradições da participação popular na definição de políticas públicas de lazer em Porto Alegre. Movimento, v. 11, n. 3, p. 9-25, 2005.

AMARAL, Silvia Cristina Franco; PEREIRA, Ana Paula Cunha. Reflexões sobre a produção em políticas públicas de educação física, esporte e lazer. Revista Brasileira de Ciências do Esporte, v. 31, n. 1, p. 41-56, 2009.

AMARAL, Silvia Cristina Franco; RIBEIRO, Olívia Cristina Ferreira; SILVA, Dirceu Santos. Produção científico-acadêmica em políticas públicas de esporte e lazer no Brasil. Motrivivência, v. 26, n. 42, p. 27-40, 2014.

AREIAS, Keni Tatiana Vazzoler; BORGES, Carlos Nazareno Ferreira. As políticas públicas de lazer na mediação entre Estado e sociedade: possibilidades e limitações. Revista Brasileira de Ciências do Esporte, v. 33, n. 3, p. 573-588, 2011.

ATHAYDE, Pedro Fernando Avalonr. O "lugar do social" na política de esporte do governo Lula. Ser Social, v. 13, n. 28, p. 184-209, 2011.

BINDER, Sarah A. Partisanship and procedural choice: institutional change in the early Congress, 1789-1823. The Journal of Politics, v. 57, n. 4, p. 1093-1118, 1995. 
BOMFIM, Silvano Andrade do. Lei geral da Copa, soberania nacional e a Constituição. Revista Brasileira de Direito Constitucional, v. 19, n. 1, p. 235-253, 2012.

BRASIL. Lei no. 9.615, de 24 de março de 1998. Institui normas gerais sobre desporto e dá outras providências. Diário Oficial da República Federativa do Brasil, Seção 1, p. 1-7, 25 Mar. 1998.

BRASIL. Lei no. 8.672, de 6 de julho de 1993. Institui normas gerais sobre desportos e dá outras providências. Diário Oficial da República Federativa do Brasil, Seção 1, p. 9379, 7 Jul. 1993.

BRASIL. Câmara dos Deputados. Projeto de Lei no. 6700 de 2013a. Acrescenta § 14 ao art. 27 da Lei no. 9.615, de 24 de março de 1998, para sujeitar os dirigentes de entidades desportivas profissionais à responsabilização civil, se houver antecipação de receitas, por meio da formalização de contratos, cujos vencimentos sejam posteriores ao término de seus mandatos. Disponível em: <https://www.camara. leg.br/proposicoesWeb/fichadetramitacao?idProposicao=599550>. Acesso em: 15 Abr. 2019.

BRASIL. Câmara dos Deputados. Projeto de Lei no. 5351 de 2013b. Altera Lei no 10.671 de 2003, o Estatuto do Torcedor para vedar sanção reflexa a torcedor na individualização de pena aplicada às entidades que especifica. Disponível em: <https:// www.camara.leg.br/proposicoesWeb/fichadetramitacao?idProposicao=571173>. Acesso em: 15 Abr. 2019.

BRASIL. Câmara dos Deputados. Resolução da Câmara dos Deputados no. 54, de 2014a. Disponível em: <https://www2.camara.leg.br/legin/fed/rescad/2014/resolucaodacamaradosdeputados-54-19-fevereiro-2014-778223-norma-pl.html>. Acesso em: 02 Abr. 2019.

BRASIL. Câmara dos Deputados. Projeto de Resolução no. 237, de 2014b. Disponível em: <https://www.camara.leg.br/proposicoesWeb/prop_mostrarintegra;jsessionid=81AA52D9E902DCBC7AF83441EF598E9A. proposicoesWebExterno2?codteor $=1230398 \&$ filename $=P R C+237 / 2014 \% 20>$. Acesso em: 02 Abr. 2019.

BRASIL. Câmara dos Deputados. Substitutivo. Brasília, s/d. Disponível em: <https:// www2.camara.leg.br/camaranoticias/noticias/70074.html>. Acesso em: 22 Abr. 2019.

CALGARO, Fernanda; PASSARINHO, Nathalia. Impasse sobre impeachment vai paralisar comissões da Câmara. G1, 16 Jan. 2016. Disponível em: <http://g1.globo.com/ politica/processo-de-impeachment-de-dilma/noticia/2016/01/impasse-sobre-impeachment-vai-paralisar-comissoes-da-camara.html>. Acesso em: 02 Abr. 2019. 
CARVALHO, César Machado. Esporte como política pública: Um estudo sobre o processo de formulação da política de esporte no Brasil. Dissertação (Mestrado em Ciência Política) - Universidade Federal de São Carlos, São Carlos, São Paulo, 2013.

CASTELAN, Lia Polegato. As conferências nacionais do esporte na configuração da política esportiva e de lazer no governo Lula (2003-2010). Dissertação (Mestrado em Educação Física) - Universidade Estadual de Campinas, Campinas, São Paulo, 2011.

COX, Gary W.; MCCUBBIN, Mathew Daniel. Legislative leviathan: party government in the House. Berkeley (CA): University of California Press, 1993.

FIGUEIREDO, Argelina; LIMONGI, Fernando. Executivo e Legislativo na nova ordem constitucional. 2. ed. Rio de Janeiro: Editora FGV, 2001.

Congresso Nacional: organização, processo legislativo e produção legal. Cadernos de Pesquisa, n. 5, São Paulo: Centro Brasileiro de Análise e Planejamento (Cebrap), 1996.

FREITAS, Andréa. O presidencialismo da coalizão. Rio de Janeiro: Fundação Konrad Adenauer, 2016a.

Unboxing the active role of the legislative power in Brazil. Brazilian Political Science Review, v. 10, n. 2, e0004, 2016b.

GOMES, Sandra. O impacto das regras de organização do processo legislativo no comportamento dos parlamentares: um estudo de caso da Assembleia Nacional Constituinte (1987-1988). Dados, v. 49, n. 1, p. 193-224, 2006.

HIRATA, Edson; FREITAS JÚNIOR, Miguel Archanjo. Bastidores do jogo: as interferências na elaboração da Lei Pelé. Projeto História: Revista do Programa de Estudos Pós-Graduados de História, v. 49, p. 119-155, 2014. Disponível em: <https://revistas.pucsp.br/revph/article/view/19053>.

HORNE, John. Sports mega-events - three sites of contemporary political contestation. Sport in Society, v. 20, n. 3, p. 328-340, 2017.

HORNE, John; MANZENREITER, Wolfram. An introduction to the sociology of sports mega-events. The Editorial Board of the Sociological Review, 2006. Disponível em: <https://journals.sagepub.com/doi/10.1111/j.1467-954X.2006.00650>.

IMMERGUT, Ellen. Health politics: interests and institutions in Western Europe. Cambridge (UK): Cambridge University Press, 1992. 
INÁCIO, Magna; REZENDE, Daniela. Partidos legislativos e governo de coalizão: controle horizontal das políticas públicas. Opinião Pública, v. 21, n. 2, p. 296-335, 2015. Disponível em: <https://doi.org/10.1590/1807-01912015212296>.

KREHBIEL, Keith. Information and legislative organization. Ann Arbor (MI): University of Michigan Press, 1992.

LIMONGI, Fernando; FIGUEIREDO, Argelina. Poder de agenda e políticas substantivas. In: INÁCIO, M.; RENNÓ, L. (Orgs.). Legislativo brasileiro em perspectiva comparada, p. 77-104. Belo Horizonte: Editora UFMG, 2009.

LINHALES, Meily Assbu. A trajetória política do esporte no Brasil: interesses envolvidos, setores excluídos. Dissertação (Mestrado) - Universidade Federal de Minas Gerais, Belo Horizonte, Minas Gerais, 1996.

MARTIN, Sean. Committees. In: MARTIN, S.; SAALFELD, T.; STR $\varnothing \mathrm{M}$, K. (Eds.). The Oxford handbook of legislative studies. Oxford (UK): Oxford University Press, 2014. Disponível em: <https://doi.org/10.1093/oxfordhb/9780199653010.001.0001>.

MARTINS, Mariana Zuaneti; VASQUEZ, Vitor. Políticas esportivas no processo legislativo brasileiro: a Comissão do Esporte em foco. In GOLIN, C. H.; SILVA, J. V. P.; PACHECO NETO, M. (Orgs.). Educação física e suas pluralidades, p. 217-240. Várzea Paulista (SP): Editora Fontoura, 2018.

MASCARENHAS, Fernando. O orçamento do esporte: aspectos da atuação estatal de FHC a Dilma. Revista Brasileira de Educação Física e Esporte, v. 30, n. 4, p. 963980, 2016. Disponível em: <https://doi.org/10.1590/1807-55092016000400963>.

MASCARENHAS, Fernando; ATHAYDE, Pedro Fernando Avalonr; SANTOS, Mariângela Ribeiro dos; MIRANDA, Natália Nascimento. O bloco olímpico: Estado, organização esportiva e mercado na configuração da agenda Rio 2016. The Journal of the Latin American Socio-cultural Studies of Sport (Alesde), v. 2, n. 2, p. 15-32, 2012.

MATIAS, Wagner Barbosa; MASCARENHAS, Fernando. A constituição do programa de modernização da gestão e de responsabilidade fiscal do futebol brasileiro (Profut): atuação parlamentar e grupos de pressão. Motrivivência, v. 30, n. 56, p. 190208, 2018.

As influências dos megaeventos esportivos na agenda e políticas esportivas: planejamento, arranjo institucional, ordenamento jurídico e financiamento. Pensar a Prática, v. 20, n. 1, 2017. Disponível em: <https://doi.org/10.5216/rpp. v20i1.34001>. 
MATTSON, Ingvar; STR $\varnothing \mathrm{M}$, Kaare. Parliamentary cCommittees. In: DÖRING, Hebert (Org.). Parliaments and majority rule in Western Europe. London: Palgrave Macmillan, 1995.

MAYHEW, David R. Congress: the electoral connection. New Haven (CT): Yale University Press, 1974.

MEDEIROS, Danilo Buscatto. Organizando maiorias, agregando preferências: a Assembleia Nacional Constituinte de 1987-1988. Dissertação (Mestrado em Ciência Política) - Universidade de São Paulo, São Paulo (SP), 2013.

MENDES, Alessandra; CODATO, Adriano. The institutional configuration of sport policy in Brazil: organization, evolution and dilemmas. Revista de Administração Pública, v. 49, n. 3, p. 563-593, 2015. Disponível em: <https://doi.org/10.1590/0034$7612125903>$.

NORTH, Douglass C. Institutions, institutional change and economic performance. Cambridge (UK): Cambridge University Press, 1990.

PEREIRA, Carlos; MUELLER, Bernardo. Uma teoria da preponderância do Poder Executivo: o sistema de comissões no Legislativo brasileiro. Revista Brasileira de Ciências Sociais, v. 15, n. 43, p. 45-67, 2000. Disponível em: <https://doi.org/10.1590/ s0102-69092000000200004>.

PRZEWORSKI, Adam. Institutions matter? Government and Opposition, v. 39, n. 4, p. 527-540, 2004. Disponível em:<https://doi.org/10.1111/j.1477-7053.2004.00134>.

REIS, Heloisa Helena Baldy dos. Lei Geral da Copa, álcool e o processo de criação da legislação sobre violência. Movimento, v. 18, n. 1, p. 69-99, 2012.

RIBEIRO, Mariângela; REIS, Nadson Santana; MATIAS, Wagner Barbosa; ATHAYDE, Pedro; HÚNGARO, Edson Marcelo; MASCARENHAS, Fernando. A agenda do futebol no governo Lula: ações rumo à Copa do Mundo Fifa 2014. Motrivivência, v. 29, n. 50, p. 90-103, 2017.

SANTOS, Fabiano. Partidos e comissões no presidencialismo de coalizão. Dados, v. 45, n. 2, p. 237-264, 2002. Disponível em: <https://doi.org/10.1590/S001152582002000200003>.

SANTOS, Fabiano; ALMEIDA, Acir. Fundamentos informacionais do presidencialismo de coalizão. Curitiba (PR): Editora Appris, 2011. 
SILVA, Dirceu Santos; MARTINS, Mariana Zuaneti; AMARAL, Sílvia Cristina Franco. General law of the 2014 Fifa World Cup Brazil. In: HOWLEY, Collin; DUN, Susan (Eds.). The Playing field: making sense of spaces and places in sporting cultures, p. 39-54. Oxford (UK): Inter-Disciplinary Press, 2016.

STAREPRAVO, Fernando Augusto; MARCHI JÚNIOR, Wanderley. (Re)pensando as políticas públicas de esporte e lazer: a sociogênese do subcampo político/burocrático do esporte e lazer no Brasil. Revista Brasileira de Ciências do Esporte, v. 38, n. 1, p. 42-49, 2016.

Políticas públicas de esporte no Brasil: uma leitura a partir da noção de (sub)campo. Pensar a Prática, v. 18, n. 4, p. 959-970, 2015.

STIGGER, Marco Paulo. Políticas sociais em lazer, esportes e participação: uma questão de acesso e de poder; ou subsídios para tomar uma posição frente à pergunta. Motrivivência, n. 11, p. 83-98, 1998. Disponível em: <https://doi.org/10.5007/\%>.

STR $\varnothing \mathrm{M}$, Kaare. Minority government and majority rule. Cambridge (UK): Cambridge University Press, 1990.

TEIXEIRA, Marcelo Resende; CARNEIRO, Fernando Henrique; MASCARENHAS, Fernando; MATIAS, Wagner Barbosa. Esporte, fundo público e pequena política: os reveses de um orçamento (r)emendado. Movimento, v. 24, n. 2, p. 593-606, 2018. Disponível em: <https://doi.org/10.22456/1982-8918.73007>.

TUBINO, Manoel José Gomes. Estudos brasileiros sobre o esporte: ênfase no esporte-educação. Maringá (PR): Eduem - UEM, 2010. Disponível em: <https://lume. ufrgs.br/handle/123456789/130>.

VASQUEZ, Vitor; DE FREITAS, Géssica. Mudanças institucionais e suas consequências: Uma análise do sistema de comissões brasileiro. CAOS - Revista Eletrônica de Ciências Sociais, v. 2, n. 23, p. 36-55, 2019.

VERONEZ, Luiz Fernando Camargo. O planejamento governamental e o orçamento do setor esportivo. Atas XV Congresso Brasileiro de Ciências do Esporte e II Congresso Internacional de Ciências do Esporte, Recife (PE), 2007.

VIGOR, Anthony; MEAN, Melissa; TIM, Charlie. After the gold rush: a sustainable Olympics for London 2012.London (UK): Institute for Public Policy Research, 2004. 